\title{
Differences in Abdominal Pain Etiology: Is it from Appendicitis or Ovarian Cyst?
}

\author{
D Hüseyin Onur AYDINa, \\ D- Ebru Hatice AYVAZOĞLU SOYa, \\ Tugan TEZCANERa, \\ D Mahir KIRNAPa
}

aDepartment of General Surgery, Başkent University Faculty of Medicine, Ankara, TURKEY

Received: 29.01.2019

Accepted: 19.03.2019

Available online: 27.03 .2019

Correspondence:

Hüseyin Onur AYDIN

Başkent University Faculty of Medicine, Department of General Surgery, Ankara, TURKEY

dronuraydin@hotmail.com
Copyright $\odot 2019$ by Türkiye Klinikleri

\begin{abstract}
Objective: In childbearing age, abdominal pain presents a unique diagnostic dilemma. These patients are often evaluated by a general surgeon and gynecologist to determine pain etiology. The aim of this study was to compare the preoperative parameters in patients with ovarian cysts, evaluate the negative appendectomy factors in patients undergoing appendectomy with acute appendicitis (AA) diagnosis, and predict negative appendectomy. Material and Methods: The medical records of patients diagnosed with AA between March 2011 and September 2018 were retrospectively evaluated. The patients were categorized into AA and normal appendix (NA) groups on the basis of postoperative pathological outcomes. The preoperative American Society of Anesthesiology scores, Alvarado scores, white blood cell count (WBC), neutrophil to lymphocyte ratio (NLR), platelet to lymphocyte ratio, cyst size, and postoperative pathological results were recorded. Results: A total of 86 patients with ovarian cyst were enrolled. In 26 (30\%) patients, NA was observed from pathology results. The best cutoff values were determined as $5.5,11.600$ cells $/ \mathrm{mm} 3,4.6$, and $19 \mathrm{~mm}$ for Alvarado score, WBC, NLR, and cyst size, respectively. Conclusion: Our study determined that the likelihood of AA increases among patients with a higher Alvarado score and WBC count and NLR increases with an increase in the likelihood of NA among patients with a larger cyst size.
\end{abstract}

Keywords: Appendicitis; ovarian cysts; acute abdomen; the predictive value of tests

7 n childbearing age, abdominal pain presents a unique diagnostic dilemma. The causes of abdominal pain are gastrointestinal, gynecological, urological, or pulmonary diseases. These patients are often evaluated by a general surgeon and gynecologist to determine pain etiology. Thorough knowledge of history and physical examination are key to differentiate the diagnosis.

Acute appendicitis (AA) is the most common abdominal surgical emergency with a rate of $27 \% .{ }^{1}$ In addition, it is the most common cause of nongynecological pelvic pain. ${ }^{2}$ It is known to occur simultaneously with various gynecological diseases. ${ }^{3}$ Ovarian cysts are frequently seen in women in reproductive age and can also cause abdominal or pelvic pain. ${ }^{4}$ In these patients with abdominal or pelvic pain, the differential diagnosis of AA and ovarian cysts is challenging. The aim of this study was to compare the preoperative parameters in patients with ovarian cysts, evaluate the negative appendectomy factors in patients undergoing appendectomy with AA diagnosis, and predict negative appendectomy.

\section{MATERIAL AND METHODS}

The medical records of patients diagnosed with AA between March 2011 and September 2018 were retrospectively evaluated. The study included 
women aged 18 to 50 years with no history of abdominal or gynecological surgery, polycystic ovarian disease, or any known ovarian disease. Among these patients, those detected to have an ovarian cyst using preoperative radiological imaging were enrolled. The patients were categorized into AA and normal appendix (NA) groups on the basis of postoperative pathology examination results.

The study was approved by the University Institutional Review Board and conducted in accordance with the principles of the Declaration of Helsinki. Written informed consent was obtained from each patient. Laparoscopic appendectomy was performed by a general surgeon who had at least 5 years of experience in laparoscopy or by a general surgery resident under the supervision of an experienced general surgeon. All operations were performed in a supine Trendelenburg and rightside-up position. After positioning the patient, three trocars were placed in the umbilical region (camera port, 10-12 mm), suprapubic region (instrument port, 10-12 mm), and left lower quadrant (instrument port, $5 \mathrm{~mm}$ ), and appendectomy was performed. The appendix stump was ligated with two 2/0 nonabsorbable loops, which were prepared extracorporeally, and the appendix was removed using an endo-bag. In the patients who underwent an open appendectomy, Mc Burney incision was performed in the right lower quadrant. After ligating the appendix stump with a $2 / 0$ nonabsorbable suture, appendectomy was performed. The preoperative American Society of Anesthesiology (ASA) scores, Alvarado scores, white blood cell count (WBC), neutrophil to lymphocyte ratio (NLR), platelet to lymphocyte ratio (PLR), cyst size, and postoperative pathological results were recorded.

Statistical analysis was performed using SPSS version 19 software program (IBM Corp., Armonk, NY, USA). Demographic and clinical characteristics were expressed as frequency and percentage for categorical data or as means and standard deviation for continuous parametric variables. Mann-Whitney $U$ test was used for nonparametric values and a logistic regression model was used to determine the significance level of the model on independent variables. The receiver operating characteristic
(ROC) analysis was performed and area under the curve was calculated to determine the cutoff values for Alvarado score, WBC, NLR, PLR, and cyst size. $\mathrm{p}<0.05$ was considered statistically significant.

\section{RESULTS}

A total of 86 patients with ovarian cyst were enrolled. Among these patients, 13 (15\%) underwent an open appendectomy, 59 (69\%) underwent a laparoscopic appendectomy, and 14 (16\%) underwent laparoscopic appendectomy and pericystectomy. In $26(30 \%)$ patients, NA was noted from pathology results. The most common symptom presented was abdominal pain, followed by bilateral lower quadrant pain [61 (71\%) and 22 (26\%), respectively]. The operative findings showed appendiceal inflammation in 54 (63\%) patients, a normally appearing appendix but ruptured ovarian cyst in 17 (20\%), and appendiceal inflammation and ovarian cyst in 15 (17\%). Age, last menstrual period, and ASA scores were similar in NA and AA groups ( $p>0.05$ ). The mean duration of symptoms was $1.8 \pm 0.9$ days in the NA group and $1.3 \pm 0.5$ days in the AA group ( $\mathrm{p}<$ 0.01 ). A significant difference was observed between the mean Alvarado scores of the NA and AA groups $(5.04 \pm 1.73$ versus $6.58 \pm 1.03$, respectively; $\mathrm{p}<0.01)$. The mean WBC counts were significantly different between the NA and AA groups $\left(11630 \pm 4340\right.$ versus $13800 \pm 3305$ cells $/ \mathrm{mm}^{3}$, respectively; $\mathrm{p}<0.01$ ). NLR was significantly higher in the AA group than the NA group $(7.73 \pm 3.36$ versus 4.93 \pm 3.8 , respectively; $\mathrm{p}<0.01$ ), whereas PLR showed a nonsignificant difference between the NA and AA groups ( $131.7 \pm 40$ versus $144 . \pm 41.7$, respectively; $\mathrm{p}>0.05)$. The mean cyst size in the NA group $(31.8 \pm 9 \mathrm{~mm})$ was significantly greater than that in the AA group $(25 \pm 10.8 \mathrm{~mm} ; \mathrm{p}<0.01)$. Table 1 summarizes the differences between the groups regarding the clinical characteristics.

The regression analysis showed that the model considering omnibus test, pathology result-dependent variable and age, symptom duration, ASA, SAT, Alvarado score, WBC, NLR, PLR, and cyst size was valid at a significance level of 0.01 . The Hosmer and Lemeshow test showed that the independent variables had a decent discriminatory 


\begin{tabular}{|c|c|c|c|c|c|c|}
\hline \multicolumn{7}{|c|}{ TABLE 1: Comparison between the groups. } \\
\hline & \multicolumn{2}{|c|}{ Normal appendix $(n=26)$} & \multicolumn{2}{|c|}{ Acute appendicitis $(n=60)$} & \multirow[b]{2}{*}{ Mann-Whitney U } & \multirow[b]{2}{*}{$p$} \\
\hline & Mean & SD & Mean & SD & & \\
\hline Age (year) & 32.8 & \pm 8.3 & 31.4 & \pm 8.6 & 699.5 & 0.449 \\
\hline Duration of complaint (day) & 1.8 & \pm 0.9 & 1.3 & \pm 0.5 & 539.5 & $0.007^{\star \star}$ \\
\hline ASA & 1.1 & \pm 0.3 & 1.1 & \pm 0.3 & 727 & 0.436 \\
\hline Last menstrual date (day) & 10.3 & \pm 4.5 & 10.2 & \pm 3.9 & 761.5 & 0.860 \\
\hline Alvarado score & 5.04 & \pm 1.73 & 6.58 & \pm 1.03 & 372.5 & $0.000^{* *}$ \\
\hline WBC cells $/ \mathrm{mm}^{3}$ & 11630 & \pm 4340 & 13800 & \pm 3300 & 489 & $0.006^{\star \star}$ \\
\hline NLR & 4.93 & \pm 3.8 & 7.73 & \pm 3.36 & 366 & $0.000^{* *}$ \\
\hline PLR & 131.7 & \pm 40 & 144.4 & \pm 41.7 & 638 & 0.182 \\
\hline Cyst size (mm) & 31.8 & \pm 9 & 25 & \pm 10.8 & 440 & $0.001^{* *}$ \\
\hline
\end{tabular}

\begin{tabular}{|c|c|c|c|c|c|}
\hline \multicolumn{6}{|c|}{ TABLE 2: The results of ROC analysis. } \\
\hline & B & SD & Wald & $P$ & $\operatorname{Exp}(B)$ \\
\hline Age & 0.013 & 0.044 & 0.095 & 0.757 & 1.014 \\
\hline Duration of complaint & -1.184 & 0.475 & 6.208 & $0.013^{*}$ & 0.306 \\
\hline ASA & 1.268 & 1.080 & 1.377 & 0.241 & 3.553 \\
\hline Last menstrual date & -0.071 & 0.083 & 0.741 & 0.389 & 0.931 \\
\hline Alvarado score & 0.803 & 0.290 & 7.692 & $0.006^{* *}$ & 2.232 \\
\hline WBC & 0.000 & 0.000 & 1.446 & 0.229 & 1.000 \\
\hline NLR & 0.212 & 0.159 & 1.786 & 0.181 & 1.236 \\
\hline PLR & 0.012 & 0.009 & 1.518 & 0.218 & 1.012 \\
\hline Cyst size & -0.047 & 0.028 & 2.914 & 0.088 & 0.954 \\
\hline
\end{tabular}

power for determining the pathology result ( $>0.01)$. Table 2 shows the predictive powers and significance levels of independent variables for predicting dependent variables. Alvarado score and time from symptom onset had a significant effect on the prediction of a pathology indicating AA $(p<0.05)$. In other words, the pathological outcome was influenced by time from symptom onset and Alvarado score. It was noted that a higher Alvarado score increased the likelihood of pathologically diagnosed AA by 2.2-fold. Although higher ASA measurements increased the likelihood of pathologically diagnosed AA by 3.5-fold, they had no meaningful effect on pathology results.

ROC analyses showed that the diagnostic powers of Alvarado score, WBC, NLR, and cyst size were statistically significant for differentiating AA and NA $(\mathrm{p}<0.05)$. The best cutoff values were determined as $5.5,11.600$ cells $/ \mathrm{mm}^{3}, 4.6$, and $19 \mathrm{~mm}$
TABLE 3: Cut-off values, considered positive if greater than or equal.

\begin{tabular}{|lccc|}
\hline Test result variable (s) & $\geq$ & Sensitivity & 1 - Specificity \\
Alvarado score & 5.5 & 0.85 & 0.38 \\
WBC $\left(\right.$ cells $\left./ \mathrm{mm}^{3}\right)$ & 11600 & 0.80 & 0.38 \\
NLR & 4.6 & 0.82 & 0.46 \\
Cyst size $(\mathrm{mm})$ & 19 & 0.78 & 0.92 \\
\hline
\end{tabular}

for Alvarado score, WBC, NLR, and cyst size, respectively. Table 3 shows the sensitivity and specificity values of these cut-off values.

\section{DISCUSSION}

Abdominal pain etiology has always been diverse in women. As ovarian pathologies may also cause abdominal pain, it is essential to differentiate between AA and gynecological diseases. The lifetime 
risk of having AA and symptomatic ovarian cysts among women has been reported to be $6.7 \%$ and approximately $7 \%$, respectively. ${ }^{5,6}$ Similar symptoms of both diseases complicate to reach a differential diagnosis. Although AA is treated surgically, simple ovarian cysts tend to regress spontaneously. In the past, negative exploration rates were approximately $20 \%$ among patients operated for a presumed diagnosis of AA; currently, the corresponding rate is lower because of the more common use of imaging techniques. ${ }^{7}$ Therefore, the two conditions must be differentiated clinically to save patients from surgical procedures. This study demonstrated that a WBC count greater than 11600 cells $/ \mathrm{mm}^{3}$, an Alvarado score greater than 5.5 , and an NLR greater than 4.6 were considerably predictive of AA, but a cyst size greater than 19 $\mathrm{mm}$ was associated with NA in patients operated for a presumed diagnosis of AA.

Leucocyte count is probably the most commonly used parameter while diagnosing AA. Although a higher leukocyte count has been reported to be the earliest laboratory sign of AA, leukocytosis seen in inflammatory processes provokes debate about the value of this test. ${ }^{8}$ Keskek et al. reported that a WBC count greater than 14300 cells $/ \mathrm{mm}^{3}$ increased the likelihood of AA. ${ }^{9}$ Our study revealed a higher leukocyte count in patients with $\mathrm{AA}$, with a level greater than 11600 cells $/ \mathrm{mm}^{3}$ having a sensitivity of $80 \%$ and specificity of $62 \%$. Leukocytosis may occur because of inflammation, physical stress, and other miscellaneous conditions. It has been used with low specificity for AA in similar studies. ${ }^{8}$ Although nonspecific for AA, leukocytosis is used as a strong biochemical predictor for its diagnosis. As it is an indicator of inflammation, it was found higher in the AA group. Alvarado score was first defined to design a treatment algorithm using clinical and laboratory signs among the patients with pain in the right lower quadrant. ${ }^{10} \mathrm{At}$ present, on the other hand, several reports have suggested a reduced clinical value in the use of advanced radiological methods. ${ }^{11}$ Although its predictive power and use have been lowered recently, it is a widely known fact that the scores of 7 or greater are a strong predictor of AA. This study demonstrated that a high Alvarado score showed that abdominal pain may be secondary to AA with a sensitivity of $85 \%$ in patients with suspected AA and coexisting ovarian cysts.

Traditionally used as an inflammatory marker, Goodman et al. first reported that NLR was more likely valuable than leukocyte count for AA diagnosis. ${ }^{12}$ Several studies conducted in the past decade have confirmed NLR as a reliable diagnostic parameter. ${ }^{13}$ This study indicates that an NLR above 4.6 (sensitivity $82 \%$, specificity $54 \%$ ) is significant for AA diagnosis as a cause of abdominal pain among patients with ovarian cysts. Other studies reported similar cutoff values for NLR for AA diagnosis. ${ }^{14}$ This discrepancy is explained by a greater increase in the blood neutrophil count than that in the lymphocyte count in the early stages of AA. ${ }^{15}$ Our patient groups similarly showed no increase in the neutrophil count in patients who did not show inflammation related to ovarian cysts, whereas an increase in inflammation was observed in patients with AA.

Simple ovarian and hemorrhagic cysts are the most common ovarian cysts. Although the majority of patients are asymptomatic, some patients may exhibit signs and symptoms of acute abdomen. ${ }^{16}$ An increase in ovarian cyst size has been shown to be related to dysmenorrhea and nonmenstrual pelvic pain. ${ }^{17}$ In this study, the measurements of cyst size revealed the reduced rate of AA among patients with larger cysts. An increase in cyst size may lead to pelvic pain because of the distention of the cyst capsule. In addition, the increased size of functional cysts such as endometrioma may increase endometriosis severity and cause abdominal pain. ${ }^{18}$

\section{CONCLUSION}

It has always been difficult to evaluate abdominal pain etiology in women. Gynecological disorders including pelvic inflammatory disease, menstrual cycle, and ovarian cysts may mimic acute abdominal pain. Particularly, ovarian cysts are common. However, AA is the most common abdominal surgical emergency. The formerly used idiom "when in doubt, take it out" nowadays loses its validity. 
Therefore, in patients with ovarian cysts, it is essential to find out the source of pain to avoid negative laparotomy. We aimed to determine the risks of negative appendectomy among patients who were operated with a presumed diagnosis of AA but have concurrent ovarian cysts. The main limitation of this study is its retrospective design. The study population was limited to a certain group including those who underwent surgery with a clinical diagnosis of AA. The diagnostic endpoint was the absence of pathological diagnoses of AA and NA. Notably, multiple causes may lead to abdominal pain, and therefore, the pain in patients with NA may not necessarily be because of an ovarian cyst. Thus, we determined that the likelihood of AA increased among patients with a higher Alvarado score and WBC count, and NLR increased with an increase in the likelihood of NA among patients with a larger cyst size. In patients having these features, observing the diagnostic steps would help reduce the negative rate of explorations. However, a need for larger prospective studies to confirm our findings still remains.

\section{Acknowledgement}

The English editing was made by "İkarus Tercüme" and statistical analyses were made by "Parantez Analiz".

\section{Source of Finance}

The study was supported by a grant from the Başkent University Research Fund.

\section{Conflict of Interest}

No conflicts of interest between the authors and / or family members of the scientific and medical committee members or members of the potential conflicts of interest, counseling, expertise, working conditions, share holding and similar situations in any firm.

\section{Authorship Contributions}

Idea/Concept: Hüseyin Onur Aydın, Ebru Hatice Ayvazoğlu Soy, Design: Hüseyin Onur Aydın, Tugan Tezcaner, Control/Supervision: Tugan Tezcaner, Mahir Kırnap, Data Collection and/or Processing: Ebru Hatice Ayvazoğlu Soy, Hüseyin Onur Aydın, Analysis and/or Interpretation: Tugan Tezcaner, Mahir Kırnap, Literature Review: Ebru Hatice Ayvazoğlu Soy, Mahir Kırnap, Writing the Article: Hüseyin Onur Aydın, Critical Review: Tugan Tezcaner, Mahir Kırnap, References and Fundings: Materials: Ebru Hatice Ayvazoğlu Soy.

\section{REFERENCES}

1. Boyd CA, Riall TS. Unexpected gynecologic findings during abdominal surgery. Curr Probl Surg. 2012;49(4):195-251. [Crossref] [PubMed] [PMC]

2. Vandermeer FQ, Wong-You-Cheong JJ. Imaging of acute abdominal pain. Clin Obstet Gynecol. 2009;52(1):2-20. [Crossref] [PubMed]

3. Song JY, Yordan E, Rotman C. Incidental appendectomy during endoscopic surgery. JSLS. 2009;13(3):376-83.

4. Raziel A, Ron-El R, Pansky M, Arieli S, Bukovsky I, Caspi E. Current management of ruptured corpus luteum. Eur J Obstet Gynecol Reprod Biol. 1993;50(1):77-81. [Crossref]

5. Addis DG, Schaffer N, Fowler B, Tauxe RV. The epidemiology of appendicitis and appendectomy in the United States. Am J Epidemiol. 1990;132(5):910-25. [Crossref] [PubMed]

6. Farghaly SA. Current diagnosis and managment of ovarian cysts. Clin Exp Obstet Gynecol. 2014;41(6):609-12.

7. Pieper $R$, Kager L, Näsman $P$. Acute appendicitis: a clinical study of 1018 cases of emergency appendectomy. Acta Chir Scand. 1982;148(1):51-62.
8. Hallan S, Asberg A, Edna TH. Additional value of biochemical test in suspected acute appendicitis. Eur J Surg. 1997;163(7):5338.

9. Keskek M, Tez M, Yoldas O, Acar A, Akgul O, Gocmen E, et al. Receiver operating characteristic analysis of leukocyte counts in operations for suspected appendicitis. Am J Emerg Med. 2008;26(7):769-72. [Crossref] [PubMed]

10. Alvarado A. A practical score for early diagnosis of acute appendicitis. Ann Emerg Med. 1986;15(5):557-64. [Crossref]

11. Al-Fouri AF, Ajarma KY, Al-Abbadi AM, Al-Omari AH, Almunaizel TS, Alzu'bi AA, et al. The Alvarado score versus computed tomography in the diagnosis of acute appendicitis: a prospective study. Med J Armed Forces India. 2016;72(4):332-7. [Crossref] [PubMed] [PMC]

12. Goodman DA, Goodman CB, Monk JS. Use of the neutrophil: lymohocyte ratio in the diagnosis of appendicitis. Am Surg. 1995;61(3): 257-9.

13. Kelly ME, Khan A, Riaz M, Bolger JC, Bennani $F$, Khan W, et al. The utilitiy of neutrophil-tolymphocyte ratio as a severity predictor of acute appendicitisi length of hospital stay and postoperative complication rates. Dis Surg. 2015;32(6):459-63. [Crossref] [PubMed]

14. Kahramanca S, Ozgehan G, Seker D, Gökce El, Seker G, Tunç G, et al. Neutrophil-tolymphocyte ratio as a predictor of acute appendicitis. Ulus Travma Acil Cerrahi Derg. 2014;20(1):19-22. [Crossref] [PubMed]

15. Hoffmann J, Rasmussen OO. Aids in the diagnosis of acute appendicitis. $\mathrm{Br} \mathrm{J}$ Surg. 1989;76(8):774-9. [Crossref] [PubMed]

16. Nemoto $Y$, Ishihara $K$, Sekiya $T$, Konishi $H$, Araki T. Ultrasonographic and clinical appearance of hemorrhagic ovarian cyst diagnosed by transvaginal scan. J Nippon Med Sch. 2003;70(3):243-9. [Crossref] [PubMed]

17. Vercellini $P$, Fedele L, Aimi G, Pietropaolo $G$, Consonni D, Crosignani PG. Association between endometriosis stage, lesion type, patient characteristics and severity of pelvic pain symptoms: a multivariate analysis of 1000 patients. Hum Reprod. 2007;22(1):26671. [Crossref] [PubMed]

18. Schliep KC, Mumford SL, Peterson CM, Chen Z, Johnstone EB, Sharp JB, et al. Pain typology and incident endometriosis. Hum Reprod. 2015;30(10):2427-38. [Crossref] [PubMed] [PMC] 